\title{
Energy-efficient Routing of Electric Vehicles with Integrated Photovoltaic Installations
}

\author{
Christian Schuss*, Tapio Fabritius*, Bernd Eichberger ${ }^{\dagger}$, and Timo Rahkonen ${ }^{\ddagger}$ \\ * Optoelectronics and Measurement Techniques (OPEM) Research Unit, University of Oulu, Finland; \\ email: christian.schuss, tapio.fabritius@oulu.fi \\ ${ }^{\dagger}$ Institute of Electronic Sensor Systems, Graz University of Technology, Austria; email: bernd.eichberger@tugraz.at \\ ${ }^{\ddagger}$ Circuits and Systems (CAS) Research Unit, University of Oulu, Finland; email: timo.rahkonen@oulu.fi
}

\begin{abstract}
This paper investigates the potential output power of photovoltaic (PV) installations on top of battery-powered electric vehicles (BEVs) and hybrid electric vehicles (HEVs). By choosing different routes within urban areas, we expect different output power levels from the vehicle's PV installation. Hence, we calculate energy profiles to estimate the PV energy which can be gained during driving conditions to choose the most energyefficient route for BEVs and HEVs. While driving duration, driving distance and traffic conditions are some of the criteria within the decision-making process of routing algorithms, in this paper, we focus on energy-efficiency of routing algorithms. We present experimental data to highlight the importance of energy profiles for improving and maximising of the electrical driving distance of BEVs and HEVs.

Index Terms - algorithm, battery-powered electric vehicle, data acquisition, energy profile, environmental data, hybrid electric vehicle, measurement, photovoltaic energy, solar energy.
\end{abstract}

\section{INTRODUCTION}

In future, due to the electrification of individual human transportation, e.g. battery-powered electric vehicles (BEVs) and hybrid electric vehicles (HEVs), and the increase in electricity demand of transportation, e.g. connected and autonomous vehicles $(\mathrm{CAVs})$, the transportation sector accounts for a large share of society's energy demand [1], [2]. It is worth noting that the vast majority of electricity consumed by $\mathrm{BEVs}$, HEVs, and CAVs is produced by non-renewable energy resources such as coal, oil, gas and nuclear power (COGN) energy sources [3], [4]. Furthermore, the electricity needed for charging these types of vehicles negatively affects the power grid [2].

It is forecasted that world's energy consumption will increase by $56 \%$ between 2010 and 2040. Over the same time period, it is estimated that global energy-related carbon dioxide emissions will increase to 45 billion metric tons in 2040, a $46 \%$ increase from 2010 [5]. In order to counteract these negative future projections for humanity, solar energy is the most promising energy resource to substitute COGN energy sources [3], [4]. However, solar energy as a power source is not only of enormous interest for energy production on a large scale, but also highly attractive on a smaller scale [6], [7].

With the integration of photovoltaic (PV) cells into the roof of vehicles, PV energy can be produced, both, under parking and driving conditions [8]-[11]. At present, passenger vehicles are only consuming energy and polluting our environment. In
2015, about 950 million passenger vehicles were in operation worldwide. The number of passenger vehicles increases year by year on a steady rate [12]. It is estimated that about $70 \%$ of the required electricity of a passenger vehicle can be produced by PV energy [13].

In terms of individual human transportation, Araki et al. [13] present the required research and development $(R \& D)$ tasks to enable photovoltaic (PV) installations on top of BEVs, HEVs and CAVs. In their work, the importance of PV simulation models is emphasised which allow to predict the potential energy of a vehicle's PV installation. Similarly, forecasts can provide vital information to drivers as how much energy can be obtained from a vehicle's PV installation [13]. In order to estimate the potential PV energy, Ota et al. [14] present a multi pyranometer array to obtain the available solar radiation level on the roof of a stationary vehicle. The focus of their work lies in measuring the direct and diffuse components of sunlight.

Recently, Toyota experimented with a solar-powered Prius. According to Toyota, the PV cells manufactured by Sharp achieve of a conversion efficiency of 34 percent-plus and are capable of providing 860 watts of power [15]. Altogether, $1,188 \mathrm{PV}$ cells were installed on Toyota's experimental vehicle: 288 PV cells on the vehicle's hoot, 576 PV cell on the vehicle's roof, and $324 \mathrm{PV}$ cells on the vehicle's rear hatch. The PV cells manufactured by Sharp, which were used by Toyota on their experimental vehicle, are smaller than the normal 156x156 mm PV cells and, thus, allowing to better utilise the available area on top of a vehicle. Even though, wide areas of the experimental vehicle's surface were used for the deployment of PV cells, some areas of the vehicle's surface remained unused on which also PV cells could be installed.

According to [15], drivers of electric vehicles fear to run out of battery, similar to users of smartphones. Hence, the aim of this research is to verify the potential PV energy which can be obtained in driving conditions and be used for extending the electrical driving range (EDR) of electric vehicles. While the driving distance, driving duration and traffic conditions are some of the criteria for choosing the best or optimal route for a vehicle, the required energy (e.g. required power from the vehicles' high-voltage battery) is another parameter and of particular interest in this research work. 
By measuring and estimating the average solar radiation level on top a vehicle which is driving within urban areas, we wish to compare the energy profile of two different routes. In addition, we wish to take into account different traffic conditions such as pedestrians crossing the street and traffic light conditions which are affecting the required energy from the vehicle's high-voltage battery. Depending on the number of electric loads such as lights, air conditioning and navigation system, entertainment system, and window wipers, for example, an electric vehicle will consume between 25 (e.g. systems in idle condition) and 1,000 watts or even more (e.g. heating the passenger cabin) when coming to a standstill. With the help of simulation models, we estimate the required energy for driving different routes as well as the possible energy from the vehicle's PV installation.

\section{BACKGROUND OF THE RESERACH}

\section{A. Output Behaviour of Photovoltiacs}

Fig. 1 illustrates the characteristic non-linear output behaviour of a PV cell in the form of the $I-V$ (Current-Voltage) curve at a PV cell temperature $\left(T_{c}\right)$ of $25{ }^{\circ} \mathrm{C}$. The point on the $I-V$ curve, in which the product of voltage and current becomes a maximum is referred to as the maximum power point (MPP). While the available power in the MPP $\left(P_{m p p}\right)$ depends on $T_{c}$, as seen in Fig. 1, $P_{m p p}$ also depends greatly on the solar radiation level $(\lambda)$.

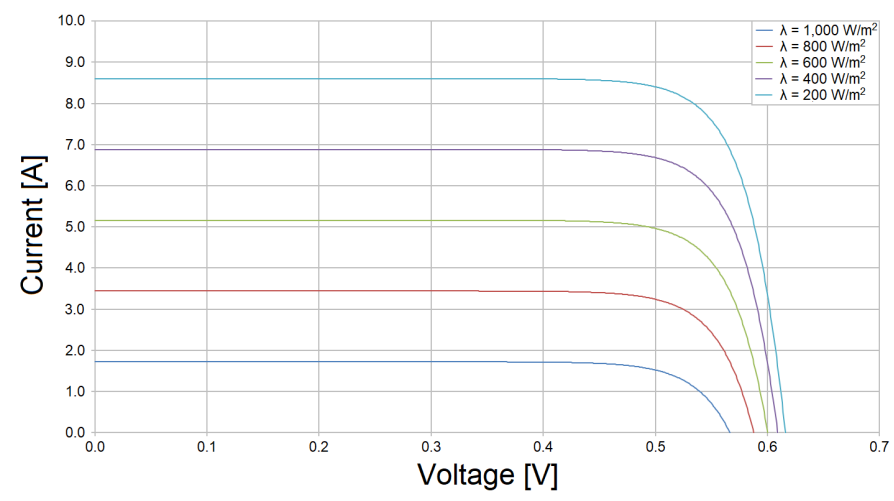

Fig. 1. $I-V$ curve of a PV cell under different solar radiation levels $(\lambda)$

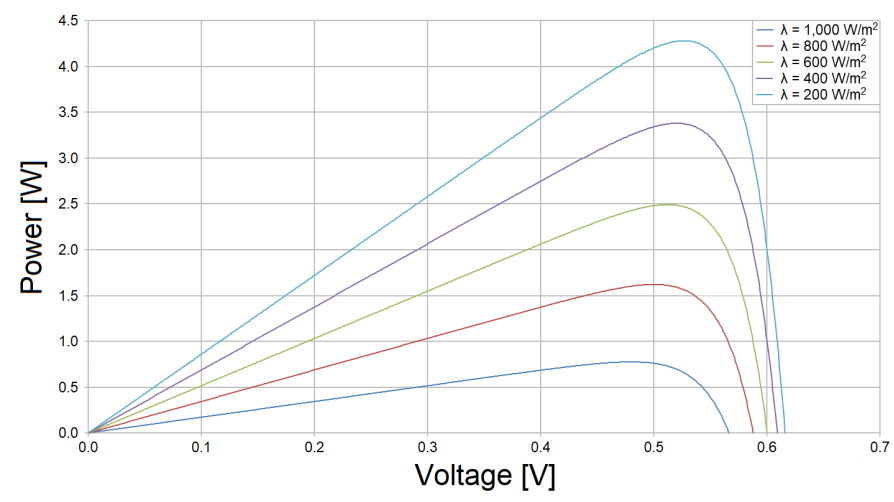

Fig. 2. $P$-V curve of a PV cell under different solar radiation levels $(\lambda)$

\section{B. Output Power of Photovoltaics}

Fig. 2 presents the $P-V$ (Power-Voltage) curve of a PV cell at a PV cell temperature $\left(T_{c}\right)$ of $25^{\circ} \mathrm{C}$. As seen in Fig. 2, the solar radiation level $(\lambda)$ determines whether less than 1 watt or more than 4 watts can be obtained from a standard (156x156 mm) silicon-based PV cell. In previous research [8], we demonstrated that due to shading from the surrounding environment, when driving in urban areas, the output power of photovoltaics will vary quickly and rapidly. In addition, it is worth noting that the alignment and interconnection of PV cells has an impact on the potential output power of photovoltaics [8], [16].

\section{EXPerimental Setup And Procedure}

\section{A. Experimental Setup}

Fig. 3 illustrates the measurement setup, more precisely a map of the streets and the two possible routes between the sports hall to the botanical garden. In the middle of the map lies the Linnanmaa campus of the University of Oulu. Route 1 consists of route $\mathrm{A}$ and the common route, while route 2 consists of route $\mathrm{B}$ and the common route. Of course, in wide urban areas, there are various ways to get from point $\mathrm{A}$ to point $B$ and vice versa. In this paper, we wish to utilse the example seen in Fig. 3 to analyse the impact on the available energy from the vehicle's PV installation by choosing between route 1 and 2 .

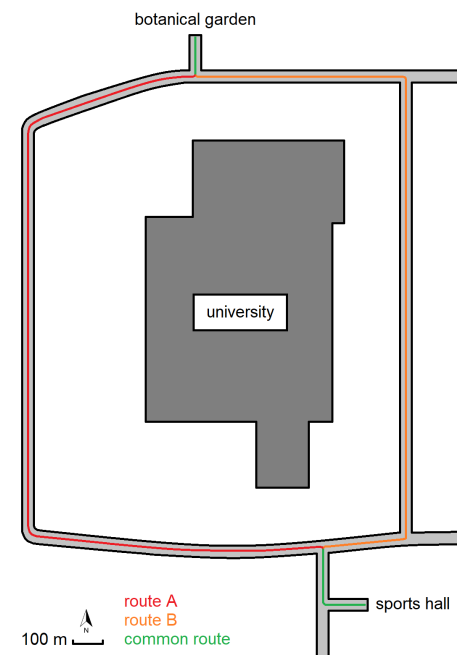

Fig. 3. Map and routes of the measurements

Based on the available information from the navigation system, route 1 and 2 result in different driving distances and durations:

route 1:

driving distance: $1.6 \mathrm{~km}$

driving duration: $3 \mathrm{~min}$

route 2 :

driving distance: $1.5 \mathrm{~km}$

driving duration: $4 \mathrm{~min}$ 
Starting from the sports hall in the South, the driver follows the common route. After a turn to the right, the driver reaches a crossing at which a choice between route 1 and 2 has to be made. Until here, the speed limit was $40 \mathrm{~km} / \mathrm{h}$. Route 1 means turning to the left-hand side, while route 2 results in turning to the right-hand side. In both directions, the speed limit is 50 $\mathrm{km} / \mathrm{h}$.

Choosing route 1 , the driver follows the street until a roundabout at which the driver turns to the right, continuing a street with a speed limit of $40 \mathrm{~km} / \mathrm{h}$. After approximately $600 \mathrm{~m}$, another roundabout is reached in which another rightturn is made. Continuing with a speed limit of $40 \mathrm{~km} / \mathrm{h}$, the driver makes a final left-turn to the common route towards the botanical garden. When choosing route 1 , the driver can cover distance quickly with $50 \mathrm{~km} / \mathrm{h}$. However, at the roundabout, short waiting times can occur, due to traffic coming from a nearby shopping centre. When driving straight, the driver passes through an area with office facilities on the left-hand side and institutes of the university on the right-hand side. As the companies are mostly unaffiliated with the university, only rarely people are crossing the street.

Choosing route 2 , the driver follows the street for a short moment, while lining up towards the left-hand side at a traffic light. After the traffic light is passed, the driver continues in a street with a speed limit of $40 \mathrm{~km} / \mathrm{h}$ for about $800 \mathrm{~m}$. Then, a left-turn is made by a right-turn $300 \mathrm{~m}$ later towards the botanical garden. When choosing route 2 , the driver has usually to wait at a traffic light. Then, the driver passes through a street with the university on the left-hand side and student apartments on the right-hand side. Throughout the day, people are passing between the university and the apartments over the various zebra crossings. There is also a primary school located at the end of the road. Hence, waiting times are expected to let people and school children cross the street.

In [8], we describe the measurement system used to obtain the solar radiation level in driving conditions. In this paper, for simplicity, we calculated the average solar radiation level $(\bar{\lambda})$ which was obtained on top of the vehicle's roof for either driving route 1 or 2 . Based on $\bar{\lambda}$, we calculated the output power in the MPP $\left(P_{m p p}\right)$ of a single PV cell. We use $P_{m p p}$ to estimate the potential PV energy for different numbers of PV cells. However, as mentioned above, in practice, each PV cell will potentially be aligned under a different longitudinal angle towards the sun based on the position of the cell on the vehicle's roof and, thus, receive a lower or higher solar radiation level than $\bar{\lambda}$.

\section{B. Experimental Model}

The obtained PV energy $\left(E_{P V}\right)$ from the vehicle's PV installation in driving conditions directly depends on the number of PV cells $\left(n_{\text {cell }}\right)$ embedded into the electric vehicle. Furthermore, the power in the MPP of one PV cell depends on the average solar radiation level $(\bar{\lambda})$. Hence, $E_{P V}$ can be obtained as follows

$$
E_{P V}=n_{\text {cell }} \times P_{m p p}(\bar{\lambda}) \times \frac{\frac{t_{d}}{3600}}{1000}
$$

where $t_{d}$ is the driving duration. Generally speaking, the longer $t_{d}$, the larger $E_{P V}$ will be. Commonly, the consumption of electric vehicle is referred in $\frac{k m}{k W h}$. Driving ranges from electricity vary from 12.5 to $17 \frac{k m}{k W h}$ [13], [17]. However, as mentioned above, while electric vehicles consume electricity during driving, similar to vehicles with combustion engines, electricity is also consumed during stationary conditions. Hence, the required energy $\left(E_{r}\right)$ by the electric vehicle for driving a certain route can be calculated as follows

$$
E_{r}=E_{d}+P_{a u x} \times \frac{\frac{t_{s}}{3600}}{1000}-E_{P V}
$$

where $E_{d}$ is the energy consumed for driving a certain distance, $P_{a u x}$ the power demand of auxiliary systems, and $t_{s}$ the duration in which is in stationary conditions. Depending on the available solar radiation level and the size of the vehicle's PV installation, the obtained PV energy $\left(E_{P V}\right)$ can be sufficiently high enough or too low to cover the demanded energy of auxiliary systems.

In addition, it is worth noting that the driving behaviour will affect both, the energy required from the vehicle's high voltage battery [18], [19] and the potential energy from the PV installation [8], [10], [20]. Hence, during the experimental measurements, we focused on a constant speed of the vehicle, based on the given speed allowance and avoided any fast acceleration and breaking during driving. Only in the case of an event, for example a red traffic light or a pedestrian crossing the street, the constant speed of the vehicle was changed.

\section{Experimental Procedure}

Generally speaking, measurements are important to understand the circumstances for PV energy production on top of moving objects. In [8], we present the measurement setup which was also used in this research work to obtain experimental data. The measurement setup itself consisted of eight probes from which simultaneously the solar radiation level $(\lambda)$ was sampled. As the irradiation of a PV cell varies depending on location of the PV cell on the roof (i.e. whether the PV cell is installed on the left-hand side or on the right-hand side of the roof, for example), we calculated the average solar radiation level $(\bar{\lambda})$ from the collected data to estimate the potential energy from the vehicle's PV installation.

\section{Experimental Results}

Tables I-III summarise the collected experimental results when driving from the sports hall in the South to the botanical garden in the North. The driving duration $\left(t_{d}\right)$ for route 1 ranged from $175.4 \mathrm{~s}$ in measurement $3(\mathrm{~m} 3)$ to $204.2 \mathrm{~s}$ in measurement $5(\mathrm{~m} 5)$, while the average solar radiation level $(\bar{\lambda})$ ranged from $424.4 \mathrm{~W} / \mathrm{m}^{2}$ in measurement $6(\mathrm{~m} 6)$ to 627.0 $\mathrm{W} / \mathrm{m}^{2}$ in measurement $2(\mathrm{~m} 2)$. Likewise, the driving duration $\left(t_{d}\right)$ for route 2 ranged from $202.8 \mathrm{~s}$ in measurement 1 (m1) to $247.9 \mathrm{~s}$ in measurement 5 (m5), while the average solar radiation level $(\bar{\lambda})$ ranged from $402.1 \mathrm{~W} / \mathrm{m}^{2}$ to $553.3 \mathrm{~W} / \mathrm{m}^{2}$. While the different events during driving have an impact on $t_{d}$ and $\bar{\lambda}, \bar{\lambda}$ is also influenced by the time of the day. 
TABLE I

DATA SET 1 (12:00 P.M. TO 01:00 P.M.)

\begin{tabular}{|c|c|c|c|c|}
\cline { 2 - 5 } \multicolumn{1}{c|}{} & \multicolumn{2}{c|}{ route 1} & \multicolumn{2}{c|}{ route 2} \\
\hline parameter & $\mathrm{m} 1$ & $\mathrm{~m} 2$ & $\mathrm{~m} 1$ & $\mathrm{~m} 2$ \\
\hline$t_{d}[\mathrm{~s}]$ & 190.7 & 181.4 & 202.8 & 216.6 \\
\hline $\bar{\lambda}\left[\mathrm{W} / \mathrm{m}^{2}\right]$ & 582.7 & 627.0 & 480.6 & 543.8 \\
\hline$E_{P V}[\mathrm{kWh}]$ & 0.0275 & 0.0283 & 0.0239 & 0.0290 \\
\hline
\end{tabular}

TABLE II

DATA SET 2 (02:30 P.M. TO 03:30 P.M.)

\begin{tabular}{|c|c|c|c|c|}
\cline { 2 - 5 } \multicolumn{1}{c|}{} & \multicolumn{2}{c|}{ route 1} & \multicolumn{2}{c|}{ route 2} \\
\hline parameter & $\mathrm{m} 3$ & $\mathrm{~m} 4$ & $\mathrm{~m} 3$ & $\mathrm{~m} 4$ \\
\hline$t_{d}[\mathrm{~s}]$ & 175.4 & 196.6 & 210.1 & 204.5 \\
\hline $\bar{\lambda}\left[\mathrm{W} / \mathrm{m}^{2}\right]$ & 588.0 & 577.3 & 553.3 & 513.1 \\
\hline$E_{P V}[\mathrm{kWh}]$ & 0.0256 & 0.0281 & 0.0287 & 0.0258 \\
\hline
\end{tabular}

TABLE III

DATA SET 3 (04:00 P.M. TO 05:00 P.M.)

\begin{tabular}{|c|c|c|c|c|}
\cline { 2 - 5 } \multicolumn{1}{c|}{} & \multicolumn{2}{c|}{ route 1 } & \multicolumn{2}{c|}{ route 2 } \\
\hline parameter & $\mathrm{m} 5$ & $\mathrm{~m} 6$ & $\mathrm{~m} 5$ & $\mathrm{~m} 6$ \\
\hline$t_{d}[\mathrm{~s}]$ & 204.2 & 182.7 & 247.9 & 206.7 \\
\hline $\bar{\lambda}\left[\mathrm{W} / \mathrm{m}^{2}\right]$ & 440.8 & 424.2 & 446.2 & 402.1 \\
\hline$E_{P V}[\mathrm{kWh}]$ & 0.0219 & 0.0188 & 0.0269 & 0.0201 \\
\hline
\end{tabular}

route 1:

m1: waiting time from common route to route A

$\mathrm{m} 2$ : no events

m3: no events

m4: waiting time from common route to route A, waiting time at the first roundabout,

waiting time from route $\mathrm{A}$ to common route

m5: waiting time from common route to route $A$

m6: waiting time from route $A$ to common route

route 2 :

m1: no events

$\mathrm{m} 2$ : $\quad$ waiting time at red traffic light

m3: $\quad$ waiting time at red traffic light

$\mathrm{m} 4$ : $\quad$ waiting time at red traffic light

m5: waiting time from common route to route B, waiting time at the school

m6: waiting time at red traffic light

Figs. 4-6 illustrate the shading due to the surrounding environment at 12:00 p.m., 02:30 p.m. and 04:00 p.m., respectively. Regarding the weather conditions during the day of the experiments, as seen Figs. 4-6, throughout the duration of the measurements, the sky was clear and direct sunlight was available. However, due different solar altitudes and positions of the sun, the available solar radiation level changed. As seen Fig. 4, at 12:00 p.m., the vehicle's roof was only shaded when turning from the common route towards route B, while in Fig. 5 , at 02.30 p.m., the vehicle's roof was only shaded when

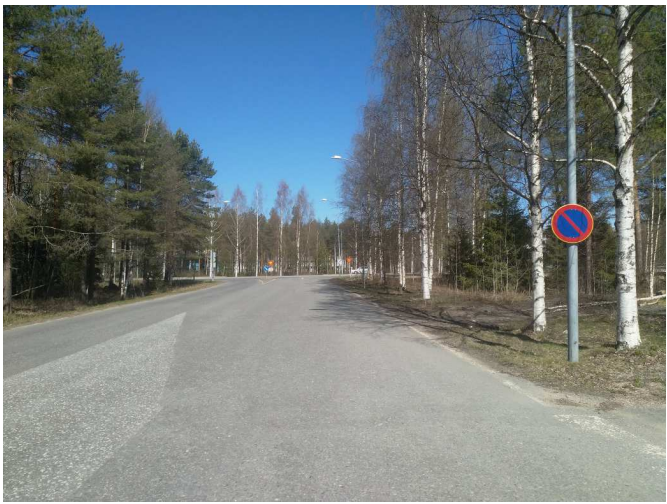

Fig. 4. Common route to route 1 and 2, situation at 12:00 p.m.

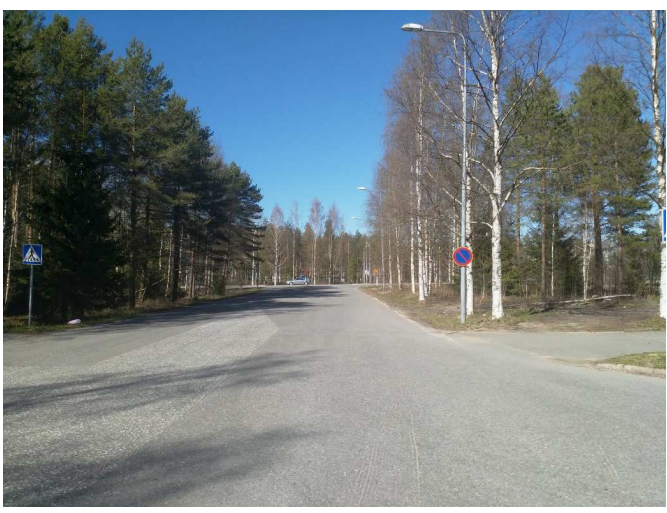

Fig. 5. Common route to route 1 and 2, situation at 02:30 p.m.

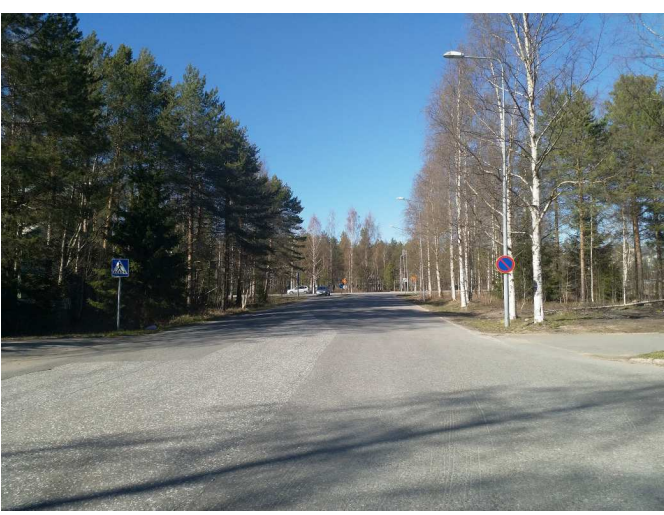

Fig. 6. Common route to route 1 and 2, situation at 04:00 p.m.

turning from the common route towards route A. As seen in Fig. 6, at 04:00 p.m., the vehicle's roof was shaded in both directions.

Fig. 7 shows the available solar radiation level $(\lambda)$ for measurement $1(\mathrm{~m} 1)$ for both, route 1 and 2 . As seen during the first $20 \mathrm{~s}$ of the measurement, when following the common route, the same $\lambda$ is obtained. At and after the crossing, when following route 1 , the vehicle's roof is exposed to direct sunlight, while when following route 2 , the available solar radiation level changes frequently between shadow and direct sunlight. However, there is not a major difference in the 
average solar radiation level $(\bar{\lambda})$ between the two routes due to a similar surrounding environment of route 1 and 2 . Thus, as seen in Tables I-III, the obtained PV energy $\left(E_{P V}\right)$ for both routes are similar as well.

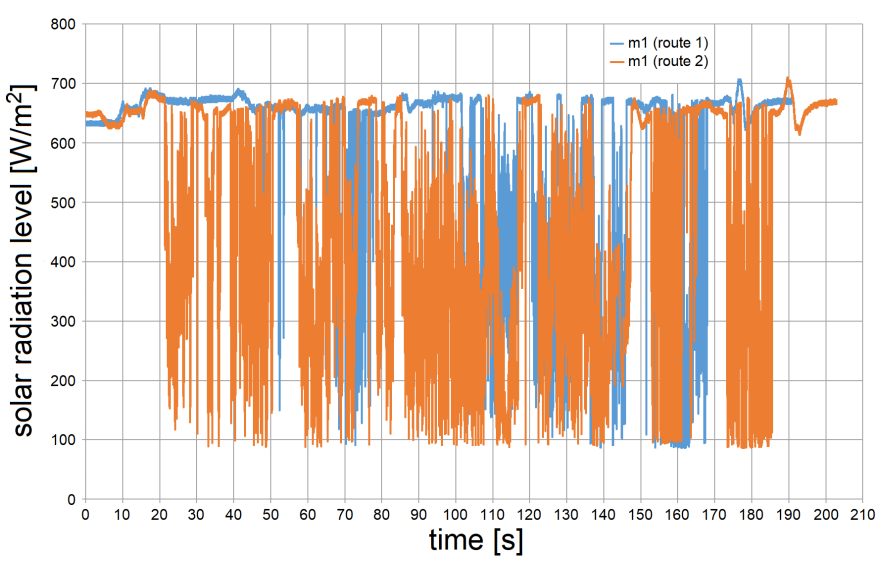

Fig. 7. m1: Solar radiation level of route 1 and 2, 12:00 p.m.

Hence, we analysed the required difference in the average solar radiation level $(\Delta \bar{\lambda})$ to choose route 1 over route 2 , obtained as follows

$$
\Delta \bar{\lambda}=\bar{\lambda}_{1}-\bar{\lambda}_{2}
$$

Generally speaking, route 2 (driving distance $1.5 \mathrm{~km}, E_{d, 2}$ $=0.0882 \mathrm{kWh}$ ) is the preferred route as the route is shorter than route 1 (driving distance $1.6 \mathrm{~km}, E_{d, l}=0.0941 \mathrm{kWh}$ ). For the simulation, we assumed that the vehicle's energy demand with $0.059 \frac{\mathrm{kWh}}{\mathrm{km}}$ (i.e. $17 \frac{\mathrm{km}}{\mathrm{kWh}}$ ) and the number of PV cells $\left(n_{\text {cell }}\right)$ as the same as for the solar-powered Toyota Prius [15]. In addition to the needed $\Delta \bar{\lambda}$, we investigated the impact of the traffic conditions by taking into account the energy consumption of auxiliary systems $\left(P_{\text {aux }}=200 \mathrm{~W}\right.$ and 1,000 W) during standstill.

Fig. 8 shows the comparison between route 1 and 2 for measurement $1(\mathrm{~m} 1)$. For $t_{s}=10 \mathrm{~s}$, without any power for the auxiliary systems, $\Delta \bar{\lambda}$ would need to increase by an additional $50 \mathrm{~W} / \mathrm{m}^{2}$ to produce enough extra PV energy to choose route 1 over route 2 . In other words, when the average solar radiation level in route $1\left(\bar{\lambda}_{1}\right)$ remains the same, the average solar radiation level in route $2\left(\bar{\lambda}_{2}\right)$ would need to decrease by 50 $\mathrm{W} / \mathrm{m}^{2}$. Likewise, $\bar{\lambda}_{1}$ would need to increase by $25 \mathrm{~W} / \mathrm{m}^{2}$, while $\bar{\lambda}_{2}$ would need to decrease by $25 \mathrm{~W} / \mathrm{m}^{2}$ so that $\Delta \bar{\lambda}=50 \mathrm{~W} / \mathrm{m}^{2}$. With $P_{\text {aux }}=1,000 \mathrm{~W}, \Delta \bar{\lambda}$ would need increase by more than $100 \mathrm{~W} / \mathrm{m}^{2}$.

Fig. 9 presents a comparison between route 1 and 2 for measurement $2(\mathrm{~m} 2)$. In here, the situation is the opposite to the previous situation. With no stops within route 1 , but a waiting time $\left(t_{s}=10 \mathrm{~s}\right)$ at the traffic light in route 2, power which is required for auxiliary during standstill affects the required energy for route $2\left(E_{r, 2}\right)$. However, with $P_{a u x}=1,000$ $\mathrm{W}, \Delta \bar{\lambda}$ need to increase by about $75 \mathrm{~W} / \mathrm{m}^{2}$ to make $E_{r}$ for both routes equal. The reason for that is in the available solar radiation level $(\lambda)$ at standstill. In route 2 , when waiting at the

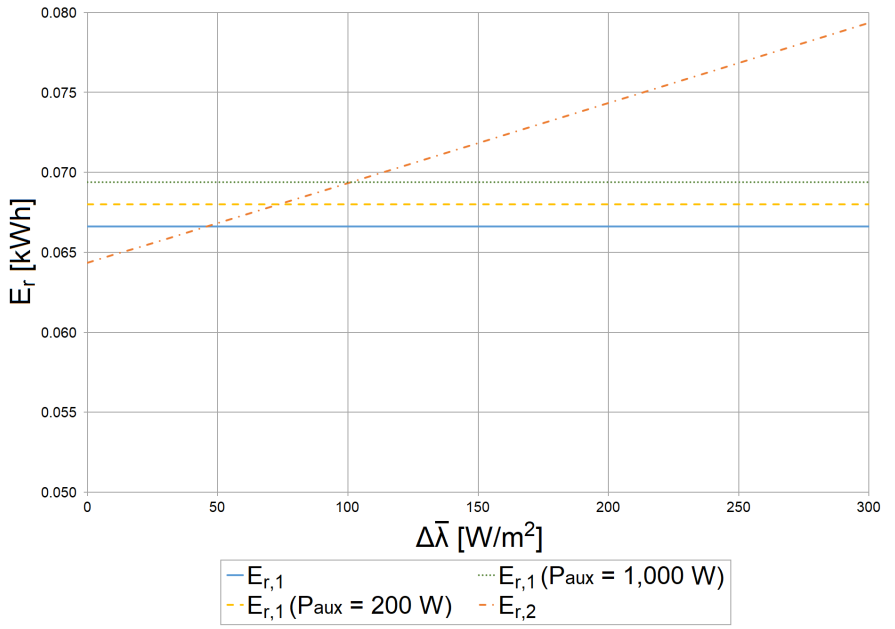

Fig. 8. m1: Comparison between route 1 and 2, 12:00 p.m.

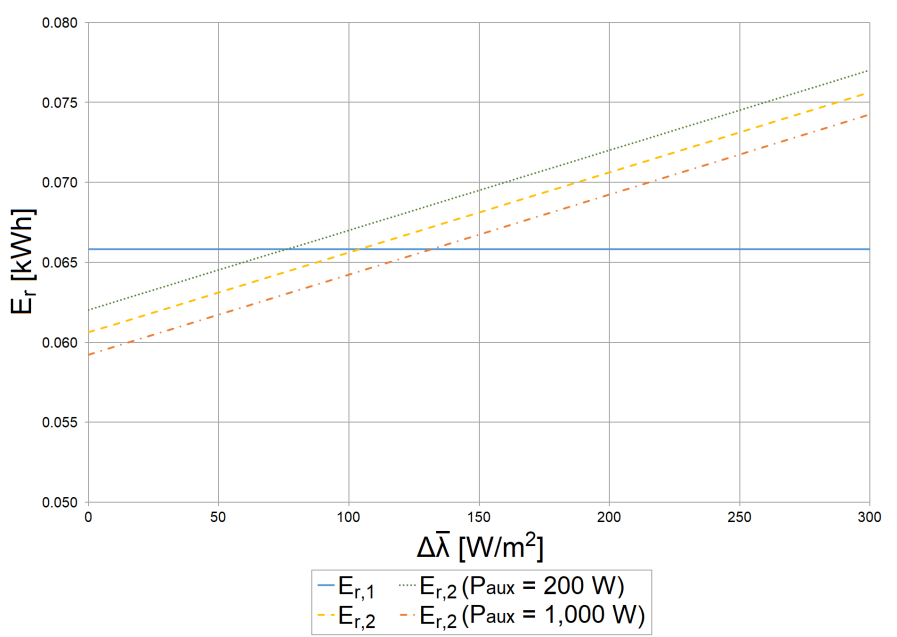

Fig. 9. m2: Comparison between route 1 and 2, 12:30 p.m.

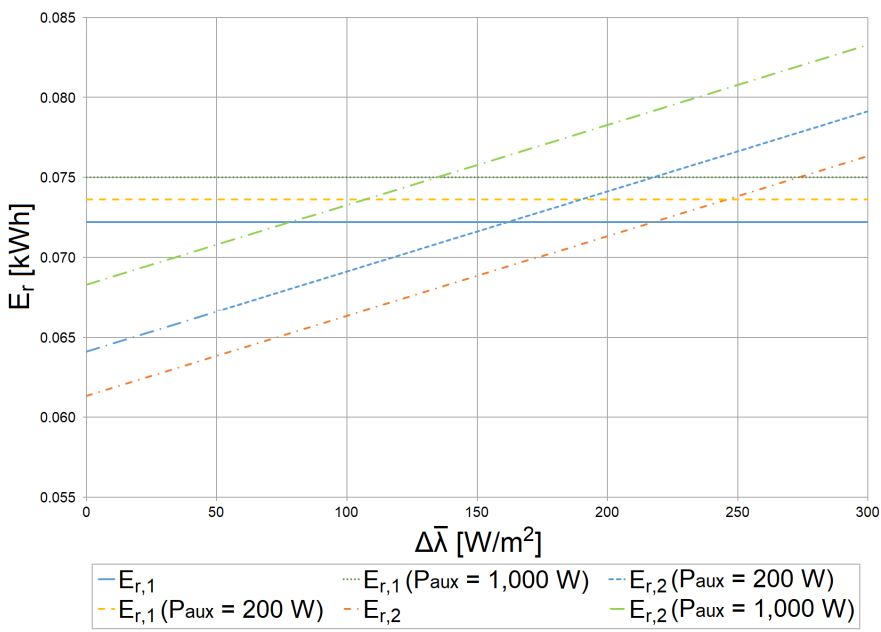

Fig. 10. m5: Comparison between route 1 and 2, 04:00 p.m.

traffic light, the vehicle's roof is exposed to direct sunlight, 
allowing the PV installation to produce a significant amount of energy during standstill. As seen in Fig. 10, waiting times and stops can also occur for both routes. In route $1, t_{s}$ was 10 $\mathrm{s}$, while $t_{s}$ was $50 \mathrm{~s}$ in route 2 .

\section{Discussion AND CONCLUSION}

PV installations on top of vehicles represent a new environment for PV energy systems. However, as on the example of the solar-powered Toyota Prius and experiments in this paper, a significant amount of PV energy $\left(E_{P V}\right)$ can be gained while driving in urban areas. The gained $E_{P V}$ can be used to reduce the required energy from the vehicle's high voltage battery $\left(E_{r}\right)$. It is worth noting that the experiments were carried out during the $15^{\text {th }}$ of May, 2019, in the City of Oulu, Finland. In other geographical regions, higher solar radiation levels are obtained, allowing to obtain a higher energy from the vehicle's PV installation. As a result, the obtained $E_{P V}$ should be taken into account when making the decision on the most energyefficient route for an electric vehicle.

However, if two routes have different driving distances, the difference in the available solar radiation level needs to be analysed carefully. Based on the experiments in this research, for a difference in the driving distance of $10 \%$, about 30 to $40 \%$ more irradiation are required to make the longer route preferable. A better efficiency of electric vehicles (i.e. better km-per-kWh ratio) and a better performance of the PV installation in terms of available output power can lower the required difference in the average solar radiation level $(\Delta \bar{\lambda})$. Traffic conditions can have an impact on the comparison of two different routes. Generally speaking, energy can be required by the electric vehicle at standstill to supply auxiliary systems such as lights, air conditioning and navigation system, entertainment system, and window wipers, for example. At the same time, with the help of the vehicle's PV installation, energy can be produced to supply auxiliary systems.

In particular during a longer stop or more frequent stops, the available irradiation on top of the vehicle can affect the average solar radiation level for the whole route. With vehicle-tovehicle (V2V) communication, data for example on the current solar radiation level and traffic conditions can be easily shared and exchanged. As electric vehicles run on a limited energy supply which is restricted by the capacity and charge status of the vehicle's high-voltage battery, the potential PV energy which can be obtained by driving different routes could be a critical factor and, in some situations, have an impact whether a driver reaches the destination or not. Generally speaking, reducing the required energy of electric vehicles is possible by maximizing the efficiency of the vehicle's PV installation.

\section{ACKNOWLEDGMENT}

Dr. Christian Schuss was funded by the Academy of Finland 6Genesis (6G) project (grant no. 318927). Prof. Tapio Fabritius is partially supported by Academy of Finlands FIRI funding (grant no. 320017). The authors would like to thank M. Schuss for her help and support in setting up and carrying out the measurements. We appreciate Harald Gall, Klaus Eberhart, and Hannes Illko for their help on this research work.

\section{REFERENCES}

[1] M. Taiebat, A.L. Brown, H.R. Safford, S. Qu, and M. Xu, "A review on energy, environmental, and sustainability implications of connected and automated vehicles, Environmental science \& technology, vol. 52, no. 20, pp. 11449-11465, 2018.

[2] N. Canter, "How will the growing use of plug-in electric vehicles affect the power grid?, TLT, vol. 74, no. 4, pp. 12-13, 2018.

[3] D.P. van Vuuren, N. Nakicenovic, K. Riahi, A. Brew-Hammond, D. Kammen, V. Modi, and K. Smith, "An energy vision: The transformation towards sustainability - interconnected challenges and solutions", Current Opinion in Environmental Sustainability, vol. 4, issue: 1, pp. 18-34, 2012.

[4] S. Mekhilef, R. Saidur, and A. Safari, "A review on solar energy use in industries", Renewable and Sustainable Energy Reviews, vol. 15, issue: 4, pp. 1777-1790, 2011.

[5] Today in Energy. EIA projects world energy consumption will increase $56 \%$ by 2040. Vol. July. Available https://www.eia.gov/todayinenergy/detail.cfm?Id=12251ł [accessed 16 September 2019], 2013.

[6] G.R.C. Mouli, P. Bauer, and M. Zeman, "System design for a solarpowered electric vehicle charging station for workplaces, Applied Energy, vol. 168, pp. 434-443, 2016.

[7] L. Cai, N. Dai, and Z. Tan, "Research on mathematical model and calculation simulation of wireless sensor solar cells in Internet of Things, Journal Wireless Communication Networks, vol. 1, p. 116, 2018.

[8] C. Schuss, T. Fabritius, B. Eichberger, and T. Rahkonen, "Moving Photovoltaic Installations: Impacts of the Sampling Rate on Maximum Power Point Tracking Algorithms, IEEE Transactions on Instrumentation and Measurement, vol. 68, no. 5, pp. 1485-1493, 2019.

[9] D. P. Birnie, III, "Analysis of energy capture by vehicle solar roofs in conjunction with workplace plug-in charging, Solar Energy, vol. 125, pp. 219-226, 2016

[10] C. Schuss, T. Kotikumpu, B. Eichberger, and T. Rahkonen, "Impact of Dynamic Environmental Conditions on the Output Behaviour of Photovoltaics, $20^{\text {th }}$ IMEKO TC4 International Symposium and $18^{\text {th }}$ International Workshop on ADC Modelling and Testing, pp. 993-998, 2014.

[11] T.L. Gibson and N.A. Kelly, "Solar photovoltaic charging of lithium-ion batteries, Proceedings of the IEEE Vehicle Power Propulsions Conference, pp. 310-316, 2009.

[12] Number of passenger cars and commercial vehicles in use worldwide from 2006 to 2015 in $(1,000$ units $)$ https://www.statista.com/statistics/281134/number-of-vehicles-in-useworldwide/ [accessed 16 September 2019], 2018.

[13] K. Araki, L. Ji, G. Kelly, and M. Yamaguchi, "To Do List for Research and Development and International Standardization to Achieve the Goal of Running a Majority of Electric Vehicles on Solar Energy", Coatings, vol. 8, issue: 7, pp. 251, 2018.

[14] Y. Ota, T. Masuda, K. Araki, and M. Yamaguchi, "A mobile multipyranometer array for the assessment of solar irradiance incident on a photovoltaic-powered vehicle", Solar Energy, vol. 184, pp. 84-90, 2019.

[15] Toyota Is Testing a New Solar-Powered Prius by D. Grossman https://www.popularmechanics.com/cars/hybridelectric/a28322554/toyota-is-testing-a-new-solar-powered-prius/ [accessed 20 November 2019], 2019.

[16] C. Schuss, H. Gall, K. Eberhart, H. Illko, and B. Eichberger, "Alignment and Interconnection of Photovoltaics on Electric and Hybrid Electric Vehicles", Proceedings of the IEEE International Instrumentation and Measurement Technology Conference (I2MTC), pp. 524-527, 2014

[17] T. Masuda, K. Araki, K. Okumura, S. Urabe, Y. Kudo, K. Kimura, T. Nakado, A. Sato, and M. Yamaguchi, "Static concentrator photovoltaics for automotive applications", Solar Energy, vol. 146, pp. 523-531, 2017.

[18] E. Gilman, G.V. Georgiev, P. Tikka, S. Pirttikangas, and J. Riekki, "How to support fuel-efficient driving?. IET Intelligent Transport Systems, vol. 12, issue: 7, pp. 631-641, 2018.

[19] K. Hu, J. Wu, and T. Schwanen, "Differences in energy consumption in electric vehicles: An exploratory real-world study in Beijing", Journal of Advanced Transportation, vol. 2017, art. no. 4695975, pp. 1-17, 2017.

[20] C. Schuss, B. Eichberger, and T. Rahkonen, "Calculating the Output Power of Photovoltaic Cells on Top of Electric and Hybrid Electric Vehicles", Proceedings of the IEEE International Instrumentation and Measurement Technology Conference (I2MTC), pp. 820-825, 2019. 